\title{
Anorectal functions after perineal and retropubic radical prostatectomy - a prospective clinical and anal manometric assessment
}

Huseyin Aydemir ${ }^{1}$, Selami Albayrak', Onder Canguven', Rahim Horuz², Cemal Goktas', Cihangir Cetinel', Adnan Giral ${ }^{3}$

${ }^{1}$ Kartal Training and Research Hospital, Istanbul, Turkey

2Osmaniye State Hospital, Osmaniye, Turkey

3 Marmara University School of Medicine, Department of Gastroenterology,

Istanbul, Turkey

Submitted: 2 May 2010

Accepted: 9 June 2020

Arch Med Sci 2011; 7, 1: 138-142

DOI: 10.5114/aoms.2011.20619

Copyright (๑) 2011 Termedia \& Banach

\section{Abstract}

Introduction: The aim of this study is to evaluate the anorectal functions of prostate cancer patients who have undergone radical perineal prostatectomy (RPP) or radical retropubic prostatectomy (RRP) surgery.

Material and methods: Thirty-seven patients with an indication for radical prostatectomy were included after informed consent. Anorectal manometry was performed before and one month after the surgery in 22 RPP and 15 RRP patients in our clinic. Clinical assessment was evaluated by anorectal functions with anal incontinence scoring (AIS) (Fernandez; no incontinence $=0$; maximal incontinence $=12$ ). Patients with a history of anorectal surgery were excluded from the study. The following data were recorded: external anal sphincteric pressure (EASP), internal anal sphincteric pressure (IASP), minimum ano-rectal reflex volume (MARRV) and minimum rectal sensory volume (MRSV).

Results: In the RPP and RRP groups, the mean age was 66 (56-75) and 64.3 (52-73) years, respectively. In the RPP group, EASP and IASP values showed a significant decrease after the surgery. In the RRP group, EASP and IASP were also decreased after the surgery, but without statistical significance. No significant change was seen in MARRV and MRSV of either group. When the scores of AIS were analysed, no significant clinical difference between pre- or post-operative scores was seen in RPP and RRP groups.

Conclusions: Perineal or retropubic surgery may injure pelvic floor muscles and/or supplying nerves, which likely causes anorectal dysfunction. Although there is a significant decrease in early postoperative EASP and IASP after RPP, it has no clinical significance according to AIS.

Key words: anal incontinence, perineum, prostate, prostatic neoplasms.

\section{Introduction}

Radical prostatectomy is an established modality in the treatment of prostate cancer. Although there have been many modifications in the surgical procedure to minimize morbidity and to increase the effectiveness of the surgery, there are two radical prostatectomy (RP) techniques, namely the retropubic and perineal ones. The other techniques which have been popularized in recent years are laparoscopic and robotic RP. The latter techniques depend on the principles of radical retropubic prostatectomy (RRP).

\author{
Corresponding author: \\ Onder Canguven MD \\ Kartal Training and Research \\ Hospital \\ Kartal Egitim ve Arastirma \\ Hastanesi \\ Anabina 9. Kat, 2. Üroloji Klinigi \\ E-5 Yolu Uzeri Cevizli-Maltepe \\ 34865 Istanbul, Turkey \\ Phone: +90 2164413900 \\ Fax: +90 2163520083 \\ E-mail: ocanguven@yahoo.com
}


Despite the better understanding of related surgical anatomy and refinement of surgical technique, surgical complications related to erectile function and urinary continence are still the main problems worsening the quality of life. In addition to the morbidities related to urinary continence and erectile function, RP, particularly the perineal one, has been related to high rates of anorectal complications. However, the number of studies concerned with this issue is limited.

Alterations in anorectal functions after RP have not received sufficient attention in urological practice. In this study, we aimed to assess anorectal functions of RRP and radical perineal prostatectomy (RPP) patients in the early postoperative period by using anal manometric measurements, and to evaluate clinical presentations of potential functional alterations.

\section{Material and methods}

Of our patients operated on with the diagnosis of localized prostate cancer, 22 RPP and 15 RRP cases were included in this study. RPP was performed through Belt's sub-sphincteric route in patients whose prostate volume was $<80 \mathrm{cc}$, sum of Gleason score [1] (GS) $\leq 7$, and prostate specific antigen (PSA) level $<10 \mathrm{ng} / \mathrm{mL}$. Patients with significant obesity and a history of surgery in the lower abdominal region were particularly selected for RPP. RRP was preferred in patients whose prostate was palpated in high localization during digital rectal examination.

The present clinical study was carried out in an academic institution and was approved by the Institutional Ethical Review Board. All patients gave their informed consent in writing before study entry. Patients with anorectal pathologies or history of anorectal surgery were excluded from the study. For each patient, a questionnaire [2] inquiring about and scoring anal incontinence was applied and then an anal manometric measurement was performed before the surgery. Manometric studies were conducted in the Motility Laboratories of the Neurological and Gastroenterologic Institutes of Marmara University Faculty of Medicine. Anal manometric measurement was repeated one month after the surgery. To evaluate anal incontinence scoring (AIS), frequency of anal incontinence presenting in the form of either gas, fluid or solid leakage was followed in a daily, weekly, and monthly manner in each patient (Table I). The AIS questionnaire was repeated one and three months after the surgery by gastroenterologists in a blind manner to eliminate bias.

Anal manometric measurements were performed in all patients preoperatively and in the first month after the surgery. In the manometric procedure, an 8-channel catheterized water perfusion system
(Andorfer Inc., Wisconsin, USA) was used. Manometric data were evaluated by using computer software (Smartgraph Rev. 3.40, Sandhill Scientific Inc., Highlands Ranch, Colorado, USA). Rectal enema was applied in every patient before the procedure. After the enema was applied, patients were placed in the left lateral decubitus position and the anorectal manometric catheter was inserted into the rectum (10 $\mathrm{cm}$ proximally from the anus). During the manometric study external anal sphincteric pressure (EASP) and IASP, maximum resting pressure, maximum squeeze pressure, squeeze time, minimum rectal sensory volume (MRSV), and minimum ano-rectal reflex volume (MARRV) were measured and recorded. Before any manometric measurements were taken, the system was calibrated for the pressures of 0 and $100 \mathrm{mmHg}$.

\section{Statistical analysis}

For statistical analysis of the data, SPSS version 15.0 (Chicago, IL, USA) was used. In evaluation of the data Student's $t$, paired samples, Wilcoxon rank, and Fisher's exact tests were used. The $p$ value $<0.05$ was accepted as statistically significant.

\section{Results}

The demographic, pathological, and operative data of the 37 patients who had RPP or RRP are presented in Table II. In 2 of 6 pathological stage T3 (pT3) patients and in 1 pT4 patient surgical margins were positive (3 of 15 cases or $20 \%$ ) in the RRP group. Concerning the early urinary continence rates of the first postoperative month, complete continence was achieved in $72.7 \%$ of RPP and $53.3 \%$ of RRP patients. Three patients in each group still have urinary incontinence and use an average of two pads per day.

\section{Clinical assessment}

In preoperative assessment it was seen that the incidence of symptoms of anal incontinence was $18.1 \%(4 / 22)$ in RPP and $13.3 \%(2 / 15)$ in RRP groups $(p>0.05)$ according to the AIS questionnaire. Preoperative average AIS score was 0.72 and 0.26 in RPP and RRP groups, respectively (Table III).

Table I. Anal incontinence scoring

\begin{tabular}{|c|c|c|c|}
\hline Frequency & Gas & Fluid & Solid \\
\hline Never & 0 & 0 & 0 \\
\hline Less than $1 /$ month & 1 & 1 & 1 \\
\hline Per montha & 2 & 2 & 2 \\
\hline Per week ${ }^{b}$ & 3 & 3 & 3 \\
\hline Per dayc & 4 & 4 & 4 \\
\hline
\end{tabular}

$a^{a} \geq 1 /$ month to $<1 /$ week $^{b} \geq 1 /$ week to $<1 /$ day, ${ }^{c} \geq 1 /$ day

Total Score (0-12): the sum of scores of gas, fluid and solid faecal incontinence 
Table II. Demographic, pathological, and operative characteristics of RPP and RRP groups

\begin{tabular}{|c|c|c|}
\hline & $\operatorname{RPP}(n=22)$ & $\operatorname{RRP}(n=15)$ \\
\hline Age [years] & $66(50-75)$ & $64(52-73)$ \\
\hline PSA [ng/ml] & $9(4.2-21)$ & $17.4(6-47.3)$ \\
\hline Biopsy GS & $6(4-7)$ & $7(5-9)$ \\
\hline \multicolumn{3}{|l|}{ Clinical stage [\%] } \\
\hline cT1 & $19(86.3)$ & $7(46.6)$ \\
\hline cT2 & $3(13.7)$ & $8(53.4)$ \\
\hline сT3 & 0 & 0 \\
\hline \multicolumn{3}{|l|}{ Pathological stage [\%] } \\
\hline pTO & 0 & $1(6.7)$ \\
\hline pT2 & $19(86.3)$ & $7(46.6)$ \\
\hline рT3 & $3(13.7)$ & $6(40)$ \\
\hline pT4 & 0 & $1(6.7)$ \\
\hline GS of RP specimen & $6(6-7)$ & $7(6-10)$ \\
\hline \multicolumn{3}{|l|}{ Surgical margin [\%] } \\
\hline Positive & $2(9.1)$ & $3(20)$ \\
\hline Negative & $20(90.9)$ & $12(80)$ \\
\hline Surgery time [min] & $132(75-180)$ & $137(90-180)$ \\
\hline Blood loss [ml] & $315(90-1500)$ & $600(50-1500)$ \\
\hline \multicolumn{3}{|l|}{ Urinary continence [\%] } \\
\hline $\begin{array}{l}\text { Complete continence } \\
\text { (first month) }\end{array}$ & $16(72.7)$ & $8(53.3)$ \\
\hline \multicolumn{3}{|l|}{ Nerve sparing surgery } \\
\hline Non-sparing & $3(13.7)$ & $7(46.7)$ \\
\hline Sparing & $19(86.3)$ & $8(53.3)$ \\
\hline
\end{tabular}

When we focused particularly on RPP patients, it was observed that $11 / 22$ (50\%) patients continued to have symptoms of anal incontinence in the first postoperative month. However, 4 of these patients were found to have anal incontinence before the surgery, and there was no increase in symptom scores in the postoperative period. Of 18 patients with no preoperative symptoms, $38.8 \%(7 / 18)$ experienced anal incontinence postoperatively in the first month. Anal incontinence resolved in 4 patients and continued in 3 out of 18 (16.6\%) patients at the end of 3 months.
Of 13 RRP patients who had normal anorectal functions preoperatively, anal incontinence symptoms developed in $15.3 \%(2 / 13)$ in the first month after surgery. Anal incontinence continued in 1 out of $13(7.7 \%)$ patients at the end of 3 months. In 2 RRP patients who had anal incontinence symptoms before the surgery, no deterioration in the symptoms was seen during the postoperative period. Postoperative first and third month average AIS scores of RPP and RRP patients are shown in Table III.

\section{Anal manometric assessment}

Preoperative and postoperative first month anal manometric assessments of RPP and RRP patients are shown in Tables IV and V, respectively. The proportion of patients whose anal sphincter squeeze time was less than 30 seconds in the postoperative period was $6.5 \%$ in RPP and $17.4 \%$ in RRP groups. No relationship between the type of surgery performed and the postoperative squeeze time was detected (Fisher's test, $p=0.630$ ).

\section{Discussion}

In this study, we evaluated anorectal functions of prostate cancer patients who had undergone RPP or RRP surgery. To our knowledge, this is the first prospective manometric study to evaluate anorectal functions after RP surgery. This study demonstrated that IASP and EASP significantly decreased in RPP surgery. Although IASP and EASP were also decreased in RRP surgery, the difference was statistically insignificant. There were also no significant changes in MARRV and MRSV of either group. When the AIS scores were analysed, no significant clinical difference between pre- and postoperative scores was seen in RPP and RRP groups.

Anal incontinence was reported in $2.2-11.5 \%$ of the general population, irrespective of different age groups [3-4]. Anal incontinence may be caused by various factors such as anorectal surgery, neurological injury, pelvic surgery, or obstetric trauma in women [5]. Surgical injury of pelvic region muscles and the anal sphincteric unit or potential neuropraxia of the related nerves during RP may result in loss of anal function. Although improved surgical techniques in RP offer better results, patients planned for RP are informed about the

Table III. Comparison of pre- and post-operative AIS of RPP and RRP groups (Wilcoxon signed ranks test)

\begin{tabular}{|lcccc|}
\hline & \multicolumn{3}{c|}{ AIS (total score) } \\
\cline { 2 - 5 } & Preoperative & $\begin{array}{c}\text { Postoperative } \\
\text { (first month) }\end{array}$ & $\begin{array}{c}\text { Postoperative } \\
\text { (third month) }\end{array}$ & $p$ \\
\hline $\operatorname{RPP}(n=22)$ & $0.72 \pm 1.80$ & $1.81 \pm 2.10$ & $0.96 \pm 2.10$ & $0.07^{\star}, 0.56^{\dagger}$ \\
\hline $\operatorname{RRP}(n=15)$ & $0.26 \pm 0.79$ & $0.73 \pm 1.94$ & $0.34 \pm 0.65$ & $0.18^{\star}, 0.46^{\dagger}$ \\
\hline
\end{tabular}

${ }^{*}$ Preoperative AIS score vs. first month; ${ }^{\dagger}$ Preoperative AIS score vs. third month 
potential negative effects of the surgery, particularly on sexual dysfunction and urinary incontinence. Previous studies indicated that faecal incontinence after RP is also a problem $[4,6]$. Moreover, it is well known that faecal incontinence has a significant impact on a person's self-confidence, personal image, and social life [6-7]. Therefore urologists should be reminded to inquire not only about urinary, but also anal, incontinence after RP.

Urologists first recognized alterations in anorectal functions after RP after the results of a study conducted by Bishoff et al. [6]. Bishoff et al. used a questionnaire to obtain data about faecal or urinary incontinence of patients operated on at least one year before. It was found that the rate of faecal incontinence was 5\% in the RRP and $18 \%$ in the RPP group. An interesting finding of the study was that the percentage of patients who sought professional help for postoperative faecal incontinence was only $7 \%$ in RRP and $14 \%$ in RPP groups [6]. Bishoff et al. emphasized that the patients should be particularly asked about postoperative anorectal functions, as they are generally reluctant to disclose their problem of anal incontinence [6]. Ruiz-Deya et al. reported that although defecation habits change in $7 \%$ (9 of 124) of patients after RPP, only $2.7 \%$ of the patients complain of anal incontinence [8].

Korman et al. suggested, however, that there is no difference in anal incontinence rates or bowel function when comparing RPP patients to RRP or control patients according to the Expanded Prostate Cancer Index Composite questionnaire [9]. Dahm et al. performed a prospective, longitudinal study of RPP patients using the bowel domain of the Expanded Prostate Cancer Index Composite questionnaire as well [4]. Dahm et al. found that the incidence of involuntary stool leakage was $15.9 \%$ (11 of 69) at 3 months and 2.9\% (2 of 69) by 12 months following RPP [4]. Kirschner-Hermanns et al., using the Modified Kelly questionnaire, found that, in the twelfth month of the RPP surgery, the most frequent symptom was soiling and difficulty in discrimination of gas and solids [10]. Kirschner-Hermanns et al. found that the incidence of involuntary stool leakage was 13\% (15 of 116) by 12 months [10]. However, 6 of the 15 patients' symptoms were related to RPP [10].

In our study, 2 of 15 RRP and 4 of 22 RPP patients had anal incontinence before the surgery. We observed that in the first and third month of the RRP anal incontinence developed in 15.3\% (2/13) and $7.7 \%(1 / 13)$ of patients who had no symptoms of anal incontinence before the surgery, respectively. In anal manometric evaluation of the RRP group, there was no significant difference between preand postoperative measurements. This finding indicates that anal incontinence may develop after
Table IV. Comparison of preoperative and postoperative first month anal manometric results of the RPP group $(n=22)$ (Wilcoxon signed ranks test, paired samples correlations)

\begin{tabular}{|lccc|}
\hline & Preoperative & $\begin{array}{c}\text { Postoperative } \\
\text { (first month) }\end{array}$ & $P$ \\
\hline IASP $[\mathrm{mmHg}]$ & $75.8 \pm 22.6$ & $61.1 \pm 20.6$ & 0.015 \\
\hline EASP $[\mathrm{mmHg}]$ & $165.6 \pm 60.7$ & $104.6 \pm 60$ & 0.006 \\
\hline MARRV [ml] & $25.0 \pm 9.6$ & $26.3 \pm 11.3$ & 0.470 \\
\hline MRSV $[\mathrm{ml}]$ & $34.0 \pm 24.4$ & $34.5 \pm 23.6$ & 0.880 \\
\hline
\end{tabular}

Table V. Comparison of preoperative and postoperative first month anal manometric results of the RRP group ( $n=15)$ (Wilcoxon signed ranks test, paired samples correlations)

\begin{tabular}{|lccc|}
\hline & Preoperative & $\begin{array}{c}\text { Postoperative } \\
\text { (first month) }\end{array}$ & $P$ \\
\hline IASP $[\mathrm{mmHg}]$ & $79.5 \pm 24.4$ & $72.4 \pm 24.5$ & 0.750 \\
\hline EASP $[\mathrm{mmHg}]$ & $206.3 \pm 69.3$ & $185 \pm 72.5$ & 0.125 \\
\hline MARRV $[\mathrm{ml}]$ & $21.3 \pm 7.4$ & $23.3 \pm 9.7$ & 0.334 \\
\hline MRSV $[\mathrm{ml}]$ & $26.0 \pm 11.8$ & $29.3 \pm 13.3$ & 0.340 \\
\hline
\end{tabular}

surgery for unclear reasons, even if no significant change occurs in the pressure of the anal canal.

In the RPP group, 7 (38.8\%) and 3 (16.6\%) out of 18 patients experienced symptoms of anal incontinence postoperatively in the first and third months, respectively. This rate appears to be higher than that of RRP. These symptomatic changes are transient and dramatically decrease over time during the postoperative period in most patients [7-8]. In a prospective study, Litwin et al. reported that anorectal functions deteriorate in the early postoperative period of RRP, and it takes 12 months or longer to resolve totally [7].

Our study and previous studies showed that anorectal functions change after RP, particularly after RPP. It is remarkable that such alterations may also be seen after RRP, although to a lesser extent [6-7]. The anal sphincter, especially the external one, is liable to be injured in the perineal surgical approach. Particularly, when Belt's subsphincteric route is preferred with the intent to preserve the external urinary sphincter with maximum safety, fibres of the external anal sphincter become liable to injury during retraction, and, therefore, sphincteric function may weaken. Our finding of a significant decrease in postoperative IASP and EASP values supports this opinion.

In addition, tension of nerves supplying the pelvic floor during RRP or RPP surgery may result in temporary denervation. Zermann et al. evaluated patients before and after RP by clinical neurourological tests, urodynamics and needle/surface electromyography [11]. The most striking finding 
was fine motor changes of pelvic floor function which cannot be explained by a pure anatomical approach [11]. Finally, postoperative potential fibrotic changes may also impede physiological functions of the continence mechanism.

When using the AIS questionnaire, potential high rates of anal incontinence may be partly a result of clinically insignificant symptoms of anal function and may be included in the scoring. For instance, anal incontinence rates of AIS may be influenced or altered by certain factors such as postoperative diarrhoea, voluntary changing of defecation habits of the patient in order to avoid possible pain or being mobilized, or passage of gas even if it has occurred only once. It is questionable why patients with only one episode of uncontrolled gas are included in the incontinent group in this scoring system. This may be one reason why the incontinence rates after RPP vary in the literature $[6,8]$. In addition, after surgery the patients may not be able to discriminate faecal content or misinterpret faecal urge. Because of such factors, questionnaires may not be reliable to assess anal incontinence when applied in the early postoperative period, and long-term assessments should be done.

A limitation of our study was the low number of study participants. However, it was very difficult to convince a patient to submit to manometric studies twice. It would also be better to obtain manometric results 1 year after surgery. Another limitation was the lack of a control group. An age-matched group could be included in the study design.

In conclusion, not only perineal but also retropubic/pelvic surgery to a lesser extent may potentially cause anorectal dysfunction, by injuring pelvic floor muscles and/or related neurological structures. Although EASP and IASP significantly decrease in the early postoperative period of RP, particularly after RPP, these laboratory findings do not exactly correlate with the postoperative clinical status of anorectal functions of the patients.

\section{Acknowledgment}

This study was presented at the EAU meeting in 2009 in Stockholm, Sweden.

\section{References}

1. Wittschieber D, Kollermann J, Schlomm T, Sauter G, Erbersdobler A. Nuclear grading versus Gleason grading in small samples containing prostate cancer: a tissue microarray study. Pathol Oncol Res 2010; 16: 479-84.

2. Fernandez-Fraga X, Azpiroz F, Malagelada JR. Significance of pelvic floor muscles in anal incontinence. Gastroenterology 2002; 123: 1441-50.

3. Nelson R, Norton N, Cautley E, Furner S. Community-based prevalence of anal incontinence. JAMA 1995; 274: 559-61.

4. Dahm P, Silverstein AD, Weizer AZ, Young MD, Vieweg J, Albala DM, Paulson DF. A longitudinal assessment of bowel related symptoms and fecal incontinence following radical perineal prostatectomy. J Urol 2003; 169: 2220-4.

5. Jorge JM, Wexner SD. Etiology and management of fecal incontinence. Dis Colon Rectum 1993; 36: 77-97.

6. Bishoff JT, Motley G, Optenberg SA, Stein CR, Moon KA, Browning SM, Sabanegh E, Foley JP, Thompson IM. Incidence of fecal and urinary incontinence following radical perineal and retropubic prostatectomy in a national population. J Urol 1998; 160: 454-8.

7. Litwin MS, McGuigan KA, Shpall Al, Dhanani N. Recovery of health related quality of life in the year after radical prostatectomy: early experience. J Urol 1999; 161: 515-9.

8. Ruiz-Deya G, Davis R, Srivastav SK, M Wise A, Thomas R. Outpatient radical prostatectomy: impact of standard perineal approach on patient outcome. J Urol 2001; 166: 581-6.

9. Korman HJ, Mulholland TL, Huang R. Preservation of fecal continence and bowel function after radical perineal and retropubic prostatectomy: a questionnaire-based outcomes study. Prostate Cancer Prostatic Dis 2004; 7: 249-52.

10. Kirschner-Hermanns R, Borchers H, Reineke T, Willis S, Jakse $\mathrm{G}$. Fecal incontinence after radical perineal prostatectomy: a prospective study. Urology 2005; 65: 337-42.

11. Zermann DH, Ishigooka $M$, Wunderlich $\mathrm{H}$, Reichelt $\mathrm{O}$, Schubert J. A study of pelvic floor function pre- and postradical prostatectomy using clinical neurourological investigations, urodynamics and electromyography. Eur Urol 2000; 37: 72-8. 